International Journal of Linguistics, Literature and Translation

ISSN: 2617-0299 (Online); ISSN: 2708-0099 (Print)

DOI: 10.32996/ijltt

Journal Homepage: www.al-kindipublisher.com/index.php/ijltt

\title{
Teachers' Perceptions of Gender Inclusive Language in the Classroom
}

\author{
Jamaica Vizcarra-Garcia 9 (iD) \\ Graduate Student, School of Advanced Studies, St. Louis University, Baguio City, Benguet, Philippines \\ Instructor, College of Teacher Education, University of Northern Philippines, Vigan City, Ilocos Sur, Philippines
}

$\checkmark$ Corresponding Author: Jamaica Vizcarra-Garcia, E-mail: jamaica.vizcarra@unp.edu.ph

\author{
ARTICLE INFORMATION \\ Received: February 02, 2021 \\ Accepted: March 08, 2021 \\ Volume: 4 \\ Issue: 3 \\ DOI: $10.32996 / i j l t .2021 .4 .3 .12$
}

\section{KEYWORDS}

Gender inclusive language, teacher education, teacher perception, feminist language planning

\section{ABSTRACT}

There is a meager investigation of teachers' views about gender-inclusive language. Considering this gap in the body of knowledge, this qualitative study sought to investigate the collective perception of higher education teachers particularly those in the teacher education program on the adoption of gender inclusive language in the classroom. Nine teachers participated in a semi-structured interview, which was recorded, transcribed and analyzed. Two themes emerged particularly (1) Communicating Instruction through Unbiased Parlance and (2) Favoring the Adoption of Gender Inclusive Language. Overall, the teachers showed an adequate understanding of gender inclusive language and unanimous support to its adoption inside the classroom as strengthened by their belief that it will promote gender equality and sensitivity among their students. Moreover, it will establish a sense of inclusivity thereby increasing student participation. Lastly, the participants believed that gender inclusive language is an evident trend in education that they cannot overlook. Hence, it is one of their responsibilities to adopt and integrate it into instruction.

\section{Introduction}

As the feminist movement emerged in the eighteenth century, more actions geared toward the elimination of gender inequality flourished. One of which is the birth of feminist linguistics. Cameron (1998) claims that the primary concern of feminist linguistics is to expose the unequal ways in which language is used and how the language structure represented men and women with prestige given more to the former. This then greatly implies that language contributes to and/or produces gender inequalities in the society (Liddicoat, 2011).

Language, with its encompassing function in people's lives and the society, is perceived as an instrument in promoting gender bias or sexism. Pauwels (1998) asserts that many languages like English have linguistic properties that reflect gender inequality. Menegatti and Rubini (2017) conforms this by claiming that language subtly reproduces the societal asymmetries of status and power in favor of men as evidenced by a number of cases wherein feminine terms are usually derived from corresponding masculine forms like the word women comes from the term men. A more popular example of language sexism evident in press communication is the use of generic masculine nouns and pronouns like man and he to represent both genders in reference to people and a nonspecific person respectively (Sensales \& Areni, 2017).

Given these realities, many put forward the need for feminist language planning (FLP). According to Liddicoat (2011, p. 1), "feminist language planning is an active engagement with the ways in which language represents and reproduces gender." Thus, it does not merely focus on how language presents women; rather it emphasizes making language support and promoting equality between men and women. Various actions relative to feminist language planning have been implemented. Pauwels (2001) in Liddicoat (2011) discussed three main projects on FLP. These are (1) adopting nonstandard conventions inspired by language experimentation and creativity instead of the usual language (ex. herstory instead of history); (2) developing a womencentered form of language adapted to the communication of women's realities; and (3) developing equality though processes of

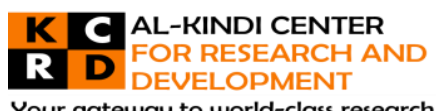

Your gateway to world-class research

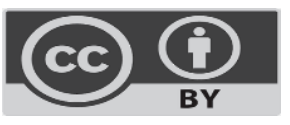

Published by Al-Kindi Center for Research and Development. Copyright (c) the author(s). This open access article is distributed under a Creative Commons Attribution (CC-BY) 4.0 license 
intervention in language. Liddicoat (2011) stressed that among these projects, it has been "the project to develop linguistic equality, which has been the most successful and the most widely considered in the language-planning literature".

Linguistic equality comes in various terms like gender fair language, gender-inclusive language, non-sexist language, and antisexist language. Different nomenclatures have been coined but all these terms are the same. Generally, gender inclusive language refers to the use of language properties like nouns and pronouns that represent all genders and does not alienate the female entity. Many policies and researches have been employed relevant to gender-inclusive language in support of FLP.

Initiatives of countries in the national level to adopt gender inclusive language and evaluate its status are recorded in a plethora of researches. Milles (2011) provided an extensive review of FLP in Sweden. Linguistic authorities initiated language reforms to eliminate gender bias in the country. These include introducing a new colloquial word "snippa" for the female genitalia and the coining of gender-neutral pronoun "hen" which is used for all genders including LGBT. Moreover, Milles (2011) reported that the Language Council of Sweden has "prepared a new official language policy for the country, which included the goal to minimize sexist tendencies in official Swedish". Bengoechea (2011) likewise analyzed the non-sexist language reforms in Spain. The promotion of non-sexist Spanish included the use of "mujer" (woman) as the head of noun phrases followed by professional/national/ethnic masculine designation as in "mujer a 'rbitro" (woman referee) instead of the feminine noun "a 'rbitra" (referee-fem), and the denunciation of the word "hombre" (man) and all masculine grammatical gender as generic representation of both genders. However, Bengoechea (2011) stressed that these reforms are likely to fail because of the lack of action to analyze the conditions in which these policies are to be implemented and for the lack of provision for its implementation. The Philippines, through Gender and Development (GAD) Code and Civil Service Commission (CSC) Memorandum Circular No. 12 series of 2005, similarly imposed a national policy to use non-sexist language in all official documents, communications and issuances.

The CSC memorandum mandated all state universities and colleges in the country to abide by the guidelines provided. This shows that the education sector is vital to promoting gender inclusive language because of its ability to reach a number of people with the services it provides. Pauwels \& Winter (2004) claimed, "education and the educational domain are identified as important catalysts in the adoption, implementation and spread of language reform (especially in relation to corpus planning)". Schools with its administrators, teachers and relevant components are greatly influential in shaping a positive behavior of learners toward gender inclusive language (Jones et al., 1997; Sunderland et al. 2000).

\section{Literature Review}

Some studies looked into gender inclusive language used by the teacher and in the classroom. Cheng and Ghajarieh (2009) analyzed the existence of gender bias in the context of "teacher-talk to students" and "student to student talk" in the classroom. Their paper provided examples of classroom discourses that contained gender bias and concluded with a number of suggestions to lessen the effect of gendered discourses in classroom settings. This is confirmed by a recent report by National Education Union and UK Feminista (2017) that revealed $66 \%$ of female students and $37 \%$ of male students in mixed-sex sixth forms have experienced or witnessed the use of sexist language in school. In addition, $64 \%$ of teachers in mixed-sex secondary schools hear sexist language in school on at least a weekly basis.

Other research endeavors on this topic revolved around the awareness and perceptions of learners on gender inclusive language. Kennedy (1993) surveyed 348 students about their knowledge of inclusive language and she found out that the respondents had minimal training and instruction in the use of non-sexist language. However, the students were ready and willing to learn about it because of their belief that non-sexist language is important. Similarly, Jacobs et al. (1998) surveyed the acceptance of gender inclusive English by Singaporean students and found that the language was viewed favorably by the majority and this was strengthened by the students' writing which presented the use of gender fair language. Bengoechea and Simon (2014) also carried a survey to evaluate the attitude of 500 university students with regard to specific Spanish non-sexist linguistic policies. However, unlike the positive results from the other studies, this showed that a great number of respondents showed hesitation on the use of dual gender. Moreover, among the identified policies, the use of feminine terms for professions acquired the highest rejection. These greatly show the resistance of the majority in accepting the policies.

Bengoechea (2011) emphasized the significance of knowing the attitudes of the linguistics community toward the language policies because these "have a major impact on the success or failure of language planning and policy". Thus, aside from investigating the perceptions of students on gender inclusive language, it is likewise important to look into the views of teachers especially that they are one of the prime agents in the implementation of these policies in the micro-level particularly in schools and universities (Pauwels and Winter, 2006). Bengoechea (2011) further stressed that "teachers' way of thinking is crucial, as they should supposedly, promote language policies in class". 
A study by Jacobs et al. (1996) explored Asian teachers' views on gender inclusive English and they found that majority of the participants used gender-exclusive materials in their classes but are willing to adopt gender inclusive English in their classes. Part of Lomotey's (2017) study likewise investigated whether teachers would like to consider using anti-sexist language alternatives in their classroom and majority of the respondents showed willingness or acceptance. Apart from these, no other research has been made available to the researcher. In addition, the aforementioned studies primarily used quantitative approach in gathering data. Considering this gap, this research intends to investigate teachers' collective view on adopting gender-inclusive language in the classroom and adding to the scanty available data on the topic.

By looking for answers to the abovementioned question, this research can provide a more in-depth information and profound insights into how teachers view gender inclusive language in the context of education. Understanding their views is essential for adopting and implementating gender inclusive language because they can influence how students perceive the same. Additionally, this study can help language planners in the macro-level by providing them information on whether there is a need to address issues in the micro-level, particularly in schools, to ascertain the success of the policies implemented and to be implemented. The result of the study may also motivate school administrators and GAD officials to monitor the sensitivity of teachers and students on the use of gender inclusive language in schools.

\section{Methodology}

This study was anchored on a qualitative approach to determine teachers' views on gender inclusive language in the classroom. Creswell (2013) defined it as a process of understanding a concept through complex and detailed exploration of various views. The researcher builds a complex, holistic picture, analyzes words, reports detailed views of informants, and conducts the study in a natural setting". It uncovers how people create meaning and knowledge through interaction in a social context.

Lafon (2006) as cited by Lombard (2017) emphasized the importance of qualitative research for language planning and implementation: "Without qualitative assessments, static surveys do not do justice to the language dynamics at play." Thus, qualitative methodology was employed.

\subsection{Participants}

The participants for the study were nine higher education instructors from one state university in the Ilocos Region. They particularly came from the College of Teacher Education. They were chosen as participants because teacher education instructors play a major role in the development of future teachers in the basic education. Their views on the topic will influence how the would-be teachers perceive the same. Social factors like gender, age, status, educational background, religion and ethnicity were not considered criteria for selecting participants because these were not variables in the research.

\subsection{Data Gathering Tools and Procedure}

The interview questions were developed through A Priori Code that guaranteed the alignment of data gathered and the intended objectives of the research. Theoretical aspects of the study were taken into account in the code to produce appropriate questions for the interview. After the interview guide was developed, an invitation to participate in the study was distributed among the teacher education faculty. The researcher proceeded in the conduct of the interview with willing participants. Tape recorder was used to record all information obtained from the interview.

In the interview, the researcher followed the guidelines identified by McNamara (2009) as cited by Turner (2010) in conducting a qualitative interview. These include 1) choosing a setting with little distraction; (2) explaining the purpose of the interview; (3) addressing terms of confidentiality; (4) explaining the format of the interview; (5) indicating how long the interview usually takes; (6) telling them how to get in touch later if they want to; (7) asking them if they have any questions before the interview starts; and (8) not counting on memory to recall their answers

\subsection{Data Analysis}

The data acquired from the interview was analyzed using Braun and Clarke (2006) thematic analysis framework. The analysis began with the researcher getting familiar with the data by reading and re-reading the interview transcripts. Then, initial coding was conducted, to identify the most significant codes. After this, codes were put together to identify the themes. The themes were then reviewed and defined through substantial discussion of teachers' perceptions of adaopting gender inclusive language in the classroom.

\section{Results and Discussion}

The systematic coding of the retrieved questionnaire and transcribed interview of the CTE instructors resulted to two themes: (1) Communicating Instruction through Unbiased Parlance and (2) Favoring the Adoption of Gender Inclusive Language. These themes were derived from significant statements from the interviews. 


\section{Communicating Instruction through Unbiased Parlance}

Teachers believe that the adoption of gender inclusive language in the classroom means that they have to use neutral language in delivering both oral and written instruction. They collectively perceive neutral language as something that is unbiased thus; it does not in any way demean or degrade a specific gender. This can be supported by one participant who views gender inclusive language as "a language that will not favor one over the other or make one superior but rather partners". Other participants believe that, "language to be used in delivering instruction should be comprehensive that all genders are included" and "the policy would mandate teachers to adopt a language that would address both genders". These responses show that the teachers understand the basics of gender inclusive language as explained by various researches (Bengoechea, 2011; Bengoechea \& Simon, 2014; Pauwels \& Winter, 2006).

It could be implied that even though the concept of gender inclusive language in relation to pedagogy has not become officially established in the country, the teachers are cognizant of its meaning and principles. This can be supported by teachers giving concrete examples of neutral language in the classroom context. To majority of participants, the use of third person pronouns and common gendered nouns should be evident in their oral discussions. As one teacher said, "In giving examples, instead of using the pronouns "he" or "she", one may generally use they, them or their." Another teacher proposed the use of neutral terms like teacher, spouse, and parent to make the classroom parlance not bias or prejudicial.

Besides using gender inclusive language in oral discussions, teachers believe that it should also be applied in instructional materials, such as books, handouts, power point presentations, and other multimedia resources. One participant specifically stated, "Pag nagbibigay ng mga situational examples lalo na sa handouts, dapat may equal exposure ang babae at lalaki para naman hindi laging lalaki ang nababanggit. (In giving situational examples especially in handouts, there should be equal exposure of both female and male in order to lessen situations when male terms are often used.)". This finding strengthens the idea that printed materials most especially books have a critical role in shaping the perspective and attitude of students toward gender inclusive language (Lee \& Collins, 2010; Jones et al., 1997). Moreover, these perceptions from teachers can support Sunderland's (2000) suggestion that teachers and pre-service teachers be mobilized to develop ways of dealing with bias found in materials like engaging in analyzing works and reversing traditional gendered language.

The examples provided by the teachers greatly emphasize the use of neutralization (Sczesny et al., 2016) as technique towards promoting gender fair language. In addition, using unmarked non-sexed terms and collective or abstract nouns as shared by the participants are similar strategies discussed by some researches (Bengoechea, 2011; Moulton et al. 1978 in Pauwels \& Winter, 2004; Schneider \& Hacker 1973) to reduce gender bias in favor of males. The similarity of responses suggests that teachers know how to fit gender inclusive language in classroom instruction particularly in teacher-centered activities like explaining concepts and giving examples.

However, it is important to note the gender inclusive language does not only revolve around the use of unbiased parlance because there are other strategies that can be employed to make the language fair for all genders. This only suggests that the teachers are only satisfactorily knowledgeable of gender inclusive language. They have a limited understanding of what adopting gender inclusive language means and its implication to teaching.

\section{Favoring the Adoption of Gender Inclusive Language}

All teacher-participants unanimously expressed agreement to the idea of adopting gender inclusive language in the classroom. They were positive about integrating the principles of gender inclusive language in all their instructional processes because it eliminates gender bias thereby encouraging gender equality. As one participant explained,

"I greatly approve of adopting this because it can serve as a medium of providing equal treatment to men and women not only in the classroom but also in society in general. More importantly, by using gender inclusive language, I can be more confident that gender bias and discrimination in the classroom is reduced."

Similarly, another teacher reasoned out,

"I approve of this policy if ever it materializes since the university caters to both male and female students. Gone are the days when men are considered the superior. Today, we celebrate equality in the society so we should remove gender bias inside the classroom. This can be achieved only if we support the use of gender inclusive language."

These responses imply that teachers strongly believe that gender-inclusive language is a medium to strengthen gender equality and emphasize its importance. For them, one effective way of promoting gender equality in the classroom is by being fair to all genders with a safe and welcoming language. Accordingly, this language plays a vital role in instilling the essence of gender equality among their students. It can also be deduced that teachers are aware and understand gender issues to have this 
particular perception. As Pauwels (2001) in Liddicoat (2011) claimed, people who are abreast of feminist projects put forward the use of gender inclusive language such as the neutral pronouns and collective and ungendered nouns to develop and disseminate equality.

Besides promoting gender equality, the use of gender inclusive language can also develop students to become gender sensitive and responsive in the future, which is why they favor its adoption in the classroom. One participant believed that, "It shapes students understanding and encourage them to be gender sensitive and responsive." Another teacher claimed that gender inclusive language can "influence students to be more conscious and sensitive of their language and actions towards gender issues".

According to Koeser et al. (2015), the exposure of people to gender fair language can trigger them to use it in future contexts thereby developing their gender sensitivity. This can be attributed to the principle of modelling or observational learning which typically occurs on a subconscious level (Koeser et al., 2015).

This reason provided by the teacher-participants conforms the findings of Koeser, Kuhn \& Sczeny (2015) that after introducing gender-fair materials to people, they become more particular to their use of language. According to them, this resulted to the "domino effect with far-reaching consequences because the more people read gender-fair forms (and are aware of it), the more likely they are to use gender-fair forms themselves". Sczesny et al. (2016) also validate that when gender fair language is constantly used for a long period, it will influence people to change especially to develop behaviors leading to the reduction of gender discrimination.

Another reason why teachers support the adoption is that it helps boost students' confidence thereby increasing student participation in class. This is evidenced by statements like, "Students will be able to build their confidence knowing that they belong." and "When students feel good about themselves because they are more willing to participate."

This perception of teachers is similar to the idea presented in the study of Cheng and Ghajarieh (2009). According to them, gender-fair discourse is important and crucial in the classroom setting because it can greatly affect the mentality of every student. Teachers' use of gendered discourse can either motivate students to do well in class or block their self-esteem. Given this, Cheng and Ghajarieh (2009) highly suggest that teachers should provide equal opportunity for both male and female students to grow by using fair discourse in the class.

Moreover, teachers believe that this particular language emphasizes inclusivity and promotes a sense of belongingness among the students, which in turn would motivate students to become more active and involved in the discussions. As Gharbavi and Mousavi (2012) claimed, when students feel excluded, alienated and devalued, they fail to empower themselves thus adversely affecting classroom performance and behavior. Amini and Birjandi (2012) likewise believed that when students particularly females are exposed to discrimination may it be in content or language, they tend to "restrict their social, behavioral and linguistic roles". Mottet, Martin, and Myers (2004) can further strengthen the idea with their finding that students take active part in the discussion and speak more if they perceived their instructors to be inclusive and appreciative of them.

The final reason teachers shared on why they favor the adoption is that it is already the newest standard in education. With gender equality becoming mainstream, teachers are more open to changes that would promote gender equality among their students. As Pauwels (2011) support, the "gender inclusive language reform is closely associated with the global trend towards more sensitive portrayal of particular groups in an attempt to eradicate racism". This is also evident in the study of Pauwels and Winter (2005) as they both claim that gender inclusive English is not particularly linked to the "inner circle" English but as a characteristic of global and international English.

According to one teacher, part of her responsibility as indicated by new standards in education is to be gender sensitive so it implies that using gender inclusive language in instruction is a mandate that she has to follow. This strongly proves that teachers are well aware of their additional duties influenced by the society. Their work does not only concern instruction but how instruction should be delivered.

United Nations Girls' Education Initiative (2011) strengthens the idea that as teachers guide students to become valuable members of the society, they have a paramount role in inspiring and influencing learners to value gender equality. The success of making students become gender responsive depends on the teacher's belief and acceptance of the responsibility put unto their hands.

Teachers' support to the adoption of gender inclusive language is evident as strengthened by the unique reasons they shared and explained. However, it is also important to consider that their approval of such may be attributed to the fact that one of the mandates of the university as directed by the 10-point agenda of the incumbent president and the Gender and Development Guidelines for Civil Service Commission is mainstreaming gender equality. Having visible directives like these may have easily influenced the participants to have affirmative opinions on the matter. As Lomotey (2017) stated, gender fair language becomes 
successful because there are legal measures to support and implement it. Winter and Pauwels (2008) also claims that the presence of guidelines or manuals for the application of gender fair language is a good strategy to promote reform.

The nature of the setting may also explain the positive regard of teachers to the adoption of gender inclusive language in the classroom. Lomotey (2017) found out that of all domains where feminist language planning could be effected, it is in formal settings like offices, schools and conferences that gender fair language is accepted and applied. People in these contexts are more open and welcoming of following "gender fair language suggestions while undertaking their responsibilities" in their social roles.

Finally, it is significant to note that this finding is similar to the findings of Jacobs et al. (1996) that Asian teachers showed greater preference to gender-inclusive English compared to gender exclusive English and Lomotey (2017) that greater number of teachers showed agreement into taking anti-sexist language alternatives into consideration in their Spanish foreign language classes. Thus, it can be deduced that the trend of making gender inclusive language be acceptable to many has been maintained.

\section{Conclusion}

This research explored the view of higher education teachers particularly those in the teacher education program on the adoption of gender inclusive language in the classroom. From the findings, it can be concluded that the teachers' understanding of the idea of adopting gender inclusive language is the use of unbiased language in communicating instruction in the classroom. This means that the language they use to discuss lessons, give examples, and develop materials should not be gender bias. Gender-indefinite terms must be used to accentuate gender equality in language.

Moreover, all teachers involved in this study expressed positive regard for the adoption of gender inclusive language. They strongly approve of applying it in their classrooms primarily because it promotes gender equality and gender sensitivity among their students. Language, for them, plays a pivotal role in making students aware about gender issues. In addition, the use of such language in the classroom would influence and shape students' mentality to adopt the same and similarly become gender sensitive teachers in the future. Another reason presented by the teachers is that it increases student participation. If teachers use gender inclusive language, students will be more willing to participate because they will feel the sense of inclusivity or belongingness. The last reason source out from the study is gender inclusive language as a norm for teachers. With the mainstreaming of gender equality, teachers acknowledge that it has become a global trend to be adopted and followed.

Given that teachers show support to the adoption of gender inclusive language in the classroom, the micro-level language planners can start developing and proposing institutional and local policies that would mandate the use of gender inclusive language in instruction. Moreover, seminars duly funded by GAD and the institutions involved may be conducted to disseminate information about what gender inclusive language is. The seminars must focus on a variety of topics that would deepen the understanding and appreciation of teachers on the adoption of this language in school. As gender equality is standardized, teachers may integrate the explicit teaching of gender inclusive language in their subjects especially to help would-be teachers to more gender-sensitive and responsive.

\section{References}

[1] Amini, M., \& Birjandi, P. (2012). Gender bias in the Iranian high school EFL textbooks. English Language Teaching, 5(2), $134-147$.

[2] Barton, A., \& Sakwa, L. M. (2012). The representation of gender in English textbooks in Uganda. Pedagogy, Culture \& Society, 20(2), 173190.

[3] Bengoechea, M. (2011). Non-sexist Spanish policies: an attempt bound to fail?, Current Issues in Language Planning, 12(1), 35-53.

[4] Bengoechea, M., \& Simón, J. (2014). Attitudes of university students to some verbal anti-sexist forms. Open Journal of Modern Linguistics, 4, 69-90.

[5] Braun, V., \& Clarke, V. (2006) Using thematic analysis in psychology. Qualitative Research in Psychology, 3 (2), 77-101

[6] Cameron, D. (1998). Feminist linguistic theories. In J. Jones (Ed.), Contemporary feminist theory (pp. 147-161). Edinburgh: Edinburgh University Press.

[7] Cheng, K. K. Y., \& Ghajarieh, A. B. B. (2009). Gendered language in the classroom. The Journal of Asia TEFL, 6(3), $27-43$.

[8] Civil Service Commission. (2005). Use of non-sexist language in all official documents, communications, and issuances. Retrieved from https://www.csguide.org/items/show/538

[9] Creswell, J.W. (2007). Qualitative inquiry and research design: Choosing among five approaches (2nd ed.). Thousand Oaks, CA: Sage Publications.

[10] Creswell, J.W. (2013). Qualitative inquiry \& research design: Choosing among five approaches (3rd ed.). Los Angeles, CA: SAGE Publications, Inc.

[11] East Asia and Pacific and South Asia Regional UNGEI. (2011). Statement of Teachers for Gender Equality. Retrieved from http://www.ungei.org/news/files/WTD 2011 statement FINAL.pdf

[12] Gharbavi, A., \& Mousavi, S.A. (2012). A content analysis of textbooks: Investigating gender bias as a social prominence in Iranian high school English textbooks. English Linguistics Research, 1(1), 4249.

[13] Hartman, P.L., \& Judd, E.L. (1978). Sexism and TESOL materials. TESOL quarterly, 12(4), 383-393. 
[14] Jones, M.A., Kitetu, C., \& Sunderland, J. (1997). Discourse roles, gender and language textbook dialogues: who learns what from John and Sally? Gender and education, 9 (4), 469-490.

[15] Kennedy, D. (1997). Nonsexist language: A progress report. Canadian Journal of Education, 18(3), 223-238.

[16] Koeser, S., Kuhn, E., and Sczesny, S. (2015). Just reading? How gender-fair language triggers readers' use of gender-fair forms. Journal of Language and Social Psychology, 34(3) $343-357$.

[17] Lee, J. F. K. (2018) Gender representation in Japanese EFL textbooks - a corpus study. Gender and Education, 30(3), 379-395.

[18] Lee, J. F. K. and Collins, P. (2010) Construction of gender: a comparison of Australian and Hong Kong English language textbooks. Journal of Gender Studies, 19(2), 121-137.

[19] Liddicoat, A. J. (2011). Feminist language planning. Current Issues in Language Planning, 12(1), 1-7.

[20] Lombard, E. (2017) Students' attitudes and preferences toward language of learning and teaching at the university of South Africa. Language Matters, 48:3, 25-48.

[21] Lomotey, B. A. (2017): Making Spanish gender fair: a review of anti-sexist language reform attempts from a language planning perspective. Current Issues in Language Planning, 19(4), 383-400.

[22] Menegatti, M. \& Rubini, M. (2017). Gender Bias and Sexism in Language. Oxford Research Encyclopedia of Communication. Retrieved from https://oxfordre.com/communication/view/10.1093/acrefore/9780190228613.001.0001/acrefore-9780190228613-e-470. Doi: 10.1093/acrefore/9780190228613.013.470

[23] Milles, K. (2011) Feminist language planning in Sweden. Current Issues in Language Planning, 12(1), 21-33.

[24] Mottet, T. P., Martin, M. M., \& Myers, S. A. (2004). Relationships among perceived instructor verbal approach and avoidance relational strategies and students' motives for communicating with their instructor. Communication Education, 53, 116122.

[25] National Education Union and UK Feminista. (2017). It's just everywhere: A study on sexism in schools- and how we tackle it. Retrieved from https://ukfeminista.org.uk/wp-content/uploads/2017/12/Report-Its-just-everywhere.pdf

[26] Pauwels, A. (1998). Women changing language. London: Longman.

[27] Pauwels, A., \& Winter, J. (2004) Gender-inclusive language reform in educational writing in Singapore and the Philippines: A corpus-based study. Asian Englishes, 7(1), 4-20.

[28] Pauwels, A., \& Winter, J. (2005a). Education and gender-inclusive language practice in English: Evidence from Singapore. Asian Journal of English Language Teaching, 15, 1-23.

[29] Pauwels, A., \& Winter, J. (2006b). Gender inclusivity of grammar rules OK?: Linguistic prescriptivism vs linguistic discrimination in the classroom. Language and Education, 20(2), 128-140.

[30] Schneider, J. W. and Hacker, S. 1973. "Sex role imagery and the use of generic 'man' in introductory texts." American Sociologist 8,12-18.

[31] Sczesny, S., Formanowicz, M., and Moser, F. (2016). Can gender-fair language reduce gender stereotyping and discrimination? Front Psychology, 7(25).

[32] Sunderland, J. (2000). New understandings of gender and language classroom research: texts, teacher talk and student talk. Language Teaching Research, 4(2), 149-173.

[33] Sunderland, J., Cowley, M., Abdul Rahim, F., Leontzakou, C., \& Shattuck, J. (2000). From bias 'in the text' to 'teacher talk around the text': an exploration of teacher discourse and gendered foreign language textbook texts. Linguistics and education, 11 (3), $251-286$

[34] Turner, D. W. (2010). Qualitative Interview Design: A Practical Guide for Novice Investigators. The Qualitative Report, 15(3), 754-760. Retrieved from https://nsuworks.nova.edu/tqr/vol15/iss3/19 